\title{
Correction to: Physics-preserving fluid reconstruction from monocular coupling with SFS and SPH
}

\author{
Xiaoying $\mathrm{Nie}^{1} \cdot$ Yong $\mathrm{Hu}^{1,2} \cdot$ Xukun Shen ${ }^{1,2}$ (D)
}

Published online: 12 August 2019

(c) Springer-Verlag GmbH Germany, part of Springer Nature 2019

\section{Correction to:}

\section{The Visual Computer}

https://doi.org/10.1007/s00371-019-01735-1

The Acknowledgements section is missing in the original article. It is given below.

Acknowledgements This work is supported by National Key R\&D Program of China (No. 2017YFB1002702). The authors sincerely thank all the anonymous reviewers for their kind suggestions.

Publisher's Note Springer Nature remains neutral with regard to jurisdictional claims in published maps and institutional affiliations.

The original article can be found online at https://doi.org/10.1007/ s00371-019-01735-1.

\section{Xukun Shen}

xkshen@buaa.edu.cn

Xiaoying Nie

niexy@buaa.edu.cn

Yong $\mathrm{Hu}$

huyong@buaa.edu.cn

1 State Key Laboratory of Virtual Reality Technology and Systems, Beihang University, Beijing 100191, China

2 School of New Media Art and Design, Beihang University, Beijing 100191, China 